\title{
The Welfare State with Private Alternatives: The Transformation of Popular Support for Social Insurance
}

\author{
Marius R. Busemeyer, University of Konstanz \\ Torben Iversen, Harvard University
}

Private alternatives to the public provision of welfare state services and benefits have expanded in almost all OECD countries over the past decades. In this paper, we study how this change affects patterns of public support for the welfare state and, in the long term, the political sustainability of solidaristic social policies. Our core argument is that the availability of private alternatives undermines support for public provision of social insurance policies, in particular among the middle and upper-income classes, whose political support is crucial for the political viability of the universalist welfare state regime. We test our theoretical claim empirically with survey data from the ISSP Role of Government module for 20 OECD countries.

$\mathrm{P}$ revious work on the future of the welfare state in advanced postindustrial democracies has emphasized their high degree of institutional stability and resilience to change. Pierson $(1994,2001)$ famously argued that welfare state policies and institutions once established create strong "lock-in" effects as beneficiary groups have material incentives to maintain (or even expand) existing policies. Yet this image of stability is hard to sustain with mounting evidence of growing class divisions over the level and structure of social spending. Building on a burgeoning new literature on privatization and welfare reforms, we argue that the new divisions are closely related to the emergence of private alternatives to public provision. Indeed, many of the insights in the existing "policy feedback" literature are reversed in a world with private alternatives.

In a seminal contribution to politics of the welfare state, Korpi and Palme (1998) argued that spending targeted to the poor, while progressive, meets with opposition in the middle and upper-middle classes, whereas an "encompassing" welfare state model, which combines basic security for everybody with an earnings-related component, would bring together the interests of the low-income and better-off citizens. In a recent test of this argument, Brady and Bostic (2015) find that low-income targeting of benefits reduces poverty, but general support for redistribution (and implicitly the welfare state) falls with low-income targeting, consistent with Korpi and Palme (1998). But like Korpi and Palme, Brady and Bostic do not systematically take into account the implications of the rise of private alternatives, which, as we will show in this paper, alters the relationship between targeting and support. The potential importance of this omission has been hinted at by Moene and Wallerstein (2001, 871), whose own argument also assumes that social protection is provided exclusively by the state: "Theoretically, the largest gap in our approach is the absence of a private alternative to publicly provided insurance. ... The politics of the demand for insurance when there is a private alternative involves different considerations." These "different considerations" are the focus of this paper.

Our core argument is that the availability of private alternatives undermines support for universalistic public provision of social insurance among the middle and upper income classes, whose political support is indeed crucial for the political viability of the welfare state. Yet, the middle class continues to support a "safety net" function for the welfare state since no private market provides effective insurance

Marius R. Busemeyer is at the University of Konstanz (Marius.Busemeyer@uni-konstanz.de). Torben Iversen is at Harvard University (tiversen@gov .harvard.edu).

Data and supporting materials necessary to reproduce the numerical results in the article are available in the JOP Dataverse (https://dataverse.harvard.edu /dataverse/jop). An online appendix with supplementary material is available at https://doi.org/10.1086/706980.

The Journal of Politics, volume 82, number 2. Published online March 4, 2020. https://doi.org/10.1086/706980

(c) 2020 by the Southern Political Science Association. All rights reserved. 0022-3816/2020/8202-0019\$10.00 
against poverty. Our paper thus points to a critical vulnerability of the universalistic welfare state, which is neglected (or at least underestimated) in the work of Brooks and Manza (2006, 2007), Esping-Andersen (1990), and Pierson (1994), as well as Korpi and Palme (1998) and many others. We show that the broad cross-class support for the universalistic welfare state that is implied by this scholarship can break down in the transition to a world with viable and high-quality private alternatives. While in Korpi and Palme the middle and uppermiddle classes will never support a means-tested system unless it is tied to a combination of universal and means-tested benefits going to higher portions of the income distribution, we show in this article that in a world where social protection is provided through the market, the middle and upper-middle classes will want all public benefits to be means tested. The relationship between benefit structure, public support, and class division therefore reverses as we move from a before private alternatives (BPA) world to an after private alternatives (APA) world. Thus, our analysis shows that the commonly held view in the literature that universalist welfare states are highly entrenched and therefore largely invulnerable to large-scale retrenchment and institutional change may no longer hold.

Many welfare states in the Western world have indeed gone through a period of privatization in the provision of welfare state services and benefits (for an overview, see Gingrich 2011; also see fig. A2 [figs. A1-A3 are available online], which shows a sharp relative increase of private vs. public social spending in OECD countries). Such privatization happened, for example, by expanding the role of private independent schools, even in a paradigmatic social democratic country like Sweden (Klitgaard 2007), by introducing choice and competition in the delivery of health care and other social services (Gingrich 2011), and by increasing the role of private capitalfunded schemes in pension regimes (Naczyk and Palier 2014). In this article, we are not explaining why privatization came about but, instead, offer a theoretical and empirical exploration of the consequences of this development for popular preferences and the future of the welfare state.

Our paper builds on a small but growing literature dealing with feedback effects of privatization on public opinion toward the welfare state. This literature, in turn, draws from the extensive literature on policy feedback in studies of welfare state attitudes (Andreß and Heien 2001; Jaeger 2006, 2009; Jordan 2013; Larsen 2008; Svallfors 1997; see Kumlin and Stadelmann-Steffen [2014] and Svallfors [2012] for recent overviews). Again, most of these studies neglect the public/private divide in their analyses and focus on dynamics within the public sector only, although recently some scholars have become interested in understanding the implications of privatization and marketization of welfare states on the class structure of attitudes. For instance, Lindh (2015) finds evidence for self-reinforcing feedback effects in the sense that support for market provision of social services is higher in countries with higher levels of private social spending. Zhu and Lipsmeyer (2015) provide similar evidence for the case of health care, complemented by Cammett, Lynch, and Bilev (2016), who find evidence that privatization of health care is associated with declining levels of trust in government. Bendz (2015) shows for the case of Sweden, which underwent marketization reforms in the delivery of health care and other services, that citizens' experiences with actively using the "exit option" from the public to the private sector increases support for further privatization (see Dowding and John [2008] for a similar study in the UK). In contrast, other work (Calzada and del Pino [2008] for Spain; Edlund [2006] for Sweden) finds little support for a self-reinforcing dynamic and concludes that public provision remains widely popular.

We seek to make sense of these sometimes conflicting findings and move beyond particular country settings by providing a model of social policy preferences that encompasses worlds with and without private alternatives and different welfare regimes. We offer a preliminary test of our model using comparative public opinion data from the International Social Survey Programme's (ISSP) 2006 module on the Role of Government. The data are linked to national-level indicators of benefit stratification and the private-public division using a multilevel regression setup that closely mirrors the formal model. Our results cover (up to) 20 OECD countries.

\section{A MODEL OF PUBLIC PROVISION WITH PRIVATE ALTERNATIVES}

In this section we formalize the intuition that preferences for public spending on social services and insurance are conditioned by the availability of private alternatives, as well as by the targeting of public benefits. We confirm the idea that there will be broad support for universal and encompassing benefits when all benefits are provided by the state-what we will refer to as the before-private-alternatives (BPA) world, which is in line with Korpi and Palme (1998). It also fits the general argument by Rothstein (1998) and others that public opposition to tax increases in the expansionary phase of welfare state development was overcome by institutions and policies to safeguard the interests of the middle classes. We derive these results in an insurance framework since it is hard to see why the middle class would ever support spending on the poor unless they themselves fear becoming poor; something Korpi and Palme's (1998) emphasis on the rational pursuit of distributive interests cannot account for.

However, in the after-private-alternatives (APA) world, broad support and solidarism breaks down, and our model 
predicts sharp divisions between those high-income voters who have the means and desire to opt out of the public system and those who stay in the system and support a large universalistic welfare state. As in Korpi and Palme (1998), in the BPA world high-income citizens are opposed to increasing public spending on benefit schemes that are targeted at the poor since this would imply a stronger degree of redistribution from the rich to the poor. In the APA world, however, our model produces the counterintuitive empirical implication, which we confirm in the empirical analysis, that incomerelated conflict over public provision of social benefits is muted if benefits are targeted to low-income citizens. The intuition is that market-based social insurance and social services can be an attractive substitute for public benefits for those with higher incomes because they involve no redistribution, yet such market-based provision provides no insurance against poverty - a fact that shores up support for a supplementary low-cost public scheme. Essentially, a minimal means-tested public system acts as a backstop to the absence of private insurance against poverty. The flip side of this argument is that high-income citizens are no longer supportive of encompassing public provision of welfare state services and benefits when viable and high-quality private alternatives are available.

Our aim is not to show that the conventional wisdom is incorrect, but that it is contingent on the (usually implicit) assumption that every social service and social insurance is publicly provided. When private alternatives are available the standard predictions are no longer valid, and they can even reverse. We believe this is an important insight because new technology, deregulation, and privatization since the 1980s have opened up many public services and forms of social insurance to private competition. Even when private alternatives are only a small share of total spending, the availability of an "outside option" profoundly affects the structure of popular preferences for public benefits and causes intensified class conflict.

To demonstrate these effects we will use a simple model to derive social policy preferences in four ideal-type scenarios (corresponding to a $2 \times 2$ table): (i) universalism in a BPA world, (ii) universalism in an APA world, (iii) means testing in a BPA world, and (iv) means testing in an APA world. We show in appendix B (apps. A-C are available online) that income graduation will not affect our conclusions as long as the welfare state is redistributive (as assumed by Korpi and Palme [1998]). ${ }^{1}$

1. We should note that our conception of the dimension of targeting of benefits ignores Korpi and Palme's discussion of the degree of coverage. As we are focusing on the recent time period, mature welfare states and unemployment and pensions as two examples of benefits schemes with a long history, there are no significant differences between countries regarding coverage.

\section{Universalism in a BPA world}

We start with a simple baseline model of government provision of a universal public service or public insurance, which is equivalent to the universalist welfare state in Korpi and Palme's terminology. The model assumes that individuals are maximizing the expected utility of after-tax income and a universal, flat-rate benefit financed by a proportional tax:

$$
W_{i}=U\left[(1-t) \cdot y_{i}\right]+\alpha \cdot U(t \cdot \bar{y}),
$$

where $y_{i}$ is $i$ 's income, $t$ is the tax rate, $\bar{y}$ is average income, and $t \cdot \bar{y}$ is the benefit. Throughout we assume a balanced budget and will show in footnotes that the assumption is always satisfied. ${ }^{2}$ Unlike the standard Meltzer-Richard model, the government is not simply transferring income but offering a service or an insurance whose demand is measured by the parameter $\alpha(>0)$.

We assume a concave utility function with standard properties: $U^{\prime}>0$ and $U^{\prime \prime}<0$. For public services and private consumption this implies declining marginal utility, and for public insurance, such as health insurance or old-age insurance, it means that people are risk averse. In the following we use a convenient log-function to represent a utility function that satisfies these conditions:

$$
W_{i}=\ln \left[(1-t) \cdot y_{i}\right]+\alpha \cdot \ln (t \cdot \bar{y}) .
$$

For insurance goods the log function implies that relative risk aversion (RRA) is equal to 1 , which is a mild degree of risk aversion (we discuss below what happens if risk aversion is higher). For social services it implies that people are willing to give up some private consumption for access to these services.

The welfare function in (2) has a maximum in $t$, which we find by setting the first-order condition equal to zero:

$$
t^{*}=\frac{\alpha}{1+\alpha} .
$$

Not surprisingly, preferred taxation is rising in the value attached to the service or insurance. ${ }^{3}$ If this benefit is valued equal to private consumption ( $\alpha=1)$, the tax rate would be one-half. More important is what is not in the equation: income does not matter for preferences, even though public provision is redistributive (in the standard sense that everyone gets

2. Here total revenues are $t \cdot \sum y_{i}$, which are paid out as lump-sum benefits to each individual: $\left(t \cdot \sum y_{i}\right) / N=t \cdot \bar{y}$. The total outlays are thus $N \cdot t \cdot \bar{y}$, which are equal to revenues. We ignore the costs of provision or any disincentive effects of benefits.

3. We assume here that $\alpha$ is common to all, although one could imagine that it varies. If the government-provided good was an insurance, for example, $\alpha$ would be a function of the individual level of risk. Our focus will be on comparative statics that is not affected by the distribution of $\alpha$, so we ignore individual heterogeneity. 
the same benefit regardless of their income and tax contribution). ${ }^{4}$ Class conflict over the welfare state is muted in this world.

This simple setup captures what we and many before us see as an essential feature of the welfare state during the golden age of expansion: broad cross-class support for government spending. For a wide range of social services and insurance programs - pensions, education, childcare, unemployment insurance, and health care - this is consistent with models that focus on insurance and public goods, as opposed to redistribution, in explaining support for the welfare state (e.g., Baldwin 1990; Estévez-Abe, Iversen, and Soskice 2001; Moene and Wallerstein 2001).

In fact, there is good reason to think that many social services and insurance programs are normal goods in the sense that higher income implies more demand. This is true even though universalism is redistributive, as long as the utility function is sufficiently concave (in insurance models, as long as RRA > 1). So support for the universalist welfare state can extend far into the middle and upper-middle classes in the BPA world. Such support would be even greater if benefits were income graduated, which, combined with a flat-rate benefit, is what Korpi and Palme call the "encompassing" welfare state. Still, Korpi and Palme assume that the encompassing welfare state is always redistributive, and they cite much evidence to that effect. For now we can ignore the issue of income graduation and simply note that the BPA universalism model fully captures two stylized facts about the postwar welfare state: $(a)$ it was indeed redistributive and (b) it enjoyed broad middle-class support.

\section{Universalism in an APA world}

What is rarely noted about the baseline model is that it assumes that all provision of services and insurance is public. For the early postwar development of the welfare state this is a reasonable approximation, at least for the majority of OECD countries. With the partial exception of the United States, (i) broad-based private insurance markets were subject to market failure and therefore underdeveloped or nonexistent, (ii) there were no markets for social services and mass education, and (iii) the financial industry was too underdeveloped and illiquid to offer credible alternatives to public pensions.

All this changed dramatically in the past three decades, in part as a result of information and communications technology (ICT) — driven maturing of financial industries (" $\mathrm{fi}$ -

4. In the special case where utility is linear or RRA $=0$ the model collapses to a Meltzer-Richard model (Meltzer and Richard 1981). Without efficiency costs everyone below the mean income would demand $t=1$ and everyone with mean income or higher would demand $t=0$. nancialization"), in part as a result of much better information about individual risks, and in part as a result of deliberate policies of deregulation and privatization. There are still areas such as unemployment insurance where private alternatives are absent or underdeveloped, ${ }^{5}$ but in most big spending categories - education, pensions, health care, and child and elderly care - there are now well-developed private options. Still, there is considerable cross-national variation in the extent to which this is true. Very broadly speaking, we have moved from a BPA to an APA world, with some variation across policy areas and countries. We take this shift, and the variation in the extent to which it has occurred, as exogenous in this paper. ${ }^{6}$

A key question is then how the growing availability of private alternatives affects mass preferences for public spending. As we noted in the introduction, there are no models that answer this question head-on. We therefore amend the baseline model to add a private alternative to public provision. This alternative is assumed to be universally available and financed by individuals spending a proportion, $p_{i}$, of their own income on private alternatives: ${ }^{7}$

$$
W_{i}=\ln \left[\left(1-t-p_{i}\right) \cdot y_{i}\right]+\alpha \cdot \ln \left(p_{i} \cdot y_{i}+t \cdot \bar{y}\right),
$$

where $p_{i} \cdot y_{i}$ is the amount spent on private alternatives.

Note that we have implicitly assumed that there are no differences in the quality of public and private provision, which could otherwise prejudice our results (although quality differences can be easily incorporated into the model without affecting our key results). Also note that (4) assumes that all individuals share in the public service, even as people are allowed to supplement it with private alternatives. An example would be buying a private health insurance that "tops up" the public plan with additional coverage and care. Another would be supplementing a basic public pension with an individual private account. Private schools also often work this way because a subsidy from the public system may pay a portion of the cost, and because private schools often piggyback on the public test system and on publicly financed teacher education. ${ }^{8}$ Still, there is always an additional individual cost, which is the private top-up spending $\left(p_{i}\right)$.

5. Although a market for private unemployment insurance is developing currently in Sweden due to recent reforms of the bourgeois government.

6. Gingrich (2011) has argued that privatization takes different forms with distinct distributive consequences. We do not disagree but here simply assume that private alternatives are always less redistributive. In an extension of the model we could allow the distribution of private benefits to vary because of regulatory constraints.

7. The balanced budget constraint is satisfied since total per capita revenues are $t \cdot \sum y_{i} / N=t \cdot \bar{y}$, and total per capita outlays are also $t \cdot \sum_{y_{i}} / N=t \cdot \bar{y}$.

8. It does not have to be like this. Consuming the private good could reduce access to the publicly provided good. This would complicate the 
The amended utility function (4) has an individual maximum, which is:

$$
t_{i}^{*}=\frac{\alpha-p_{i} \cdot\left(\alpha+r_{i}\right)}{1+\alpha}
$$

where $r_{i}=y_{i} / \bar{y}$ is relative income. Note that if $p_{i}>0$, the preferred level of taxation and public spending is lower than in a public-only system. Moreover, and this is key, with private spending higher income is now associated with lower support for public spending. This is because higher income makes the private alternative relatively more attractive as it is directly proportional to income whereas the public system is flat-rate (or, in a less redistributive "encompassing" setup, partially earnings related). This result holds regardless of the degree of risk aversion (or concavity of the utility function), and it means that the preferences over taxation and public spending will now be divided by class.

The severity of this cleavage depends on the number who opt into the private alternatives and at what level of income. In appendix $\mathrm{A}(\mathrm{i})$ we show that the threshold at which people opt into private alternatives depends on the tax rate because taxes crowd out private spending, but some always will. Among those who do, even if just to "top up" their public insurance, the preferred tax rate is zero. In an APA world there can thus be a sharp division of preferences between those who are above and those who are below the threshold. This is also true if public benefits are in part earnings related, as opposed to being entirely flat-rate, which corresponds to Korpi and Palme's "encompassing" welfare state. As long as there is some redistributive element in public spending, those opting into private alternatives have an incentive to oppose. ${ }^{9}$

In a world of incomplete information, the threshold will be less deterministic. People will not have precise information about their relative income, and it is unlikely that they know exactly how changes in public spending will affect their own welfare. They may also not know the relative "quality" or efficiency of public and private provision and may furthermore be motivated by more subjective assessments of the

model because it implies network effects: when others increase their private spending the cost of public service provision goes down. Such network effects can be important in accounting for different private-public spending equilibria, as we have shown in Busemeyer and Iversen (2014). Here we keep such differences as exogenous and consider only the structure of public policy preferences.

9. Below we consider the (more realistic) possibility that not all risks can be covered in the private market, notably the risk of becoming poor. This implies a less sharp division over public spending and in app. A we show that when benefits for the poor and nonpoor cannot be unbundled, support for public spending among those who have opted into the market can be high, even as they prefer to reduce spending on the nonpoor. value of individual choice, and so on. As analysts we do not know all these pieces of the individual choice, and we will treat it as random noise, but we can reasonably expect that the "objective" distance from the threshold will affect the likelihood favoring cuts to spending. Hence:

$$
\begin{aligned}
\operatorname{Pr}(\text { support for cuts }) & =\operatorname{Pr}\left[r_{i}>\frac{t}{1-t}+u_{i}\right] \\
& =\operatorname{Pr}\left[r_{i}-\frac{t}{1-t}>u_{i}\right]
\end{aligned}
$$

where $u_{i} \sim N\left(0, \sigma_{i}^{2}\right)$ is a normally distributed error term. All the variations of our basic model can be expressed in a probabilistic form such as (6), and this is convenient since it can be estimated by standard statistical models (we use logistic regression).

\section{Targeted means-tested benefits in a BPA world}

The previous analysis assumes universal, lump-sum benefits, but what happens if benefits are targeted to people with low income? This corresponds to a means-tested system in the standard Esping-Andersen terminology (adopted by Korpi and Palme). To answer this question, we first consider the BPA case: ${ }^{10}$

$$
W_{i}=\left(1-\pi_{i}\right) \cdot \ln \left[(1-t) \cdot y_{i}\right]+\pi_{i} \cdot \alpha \cdot \ln \left(\frac{t \cdot \bar{y}}{n}\right),
$$

where $n$ is the share of the population who are poor, and $\pi_{i}$ is the probability of falling below the income eligibility threshold for benefits in the next period, assuming that people look only one period into the future. ${ }^{11}$ Seen from the perspective of someone who is not poor, the optimal tax rate is:

$$
t^{\star}=\frac{\alpha}{1 / \pi_{i}-1+\alpha} \text {. }
$$

This result differs from the case of universalistic benefits because the demand for spending now depends on the probability of becoming poor. If that probability approximates zero, the preferred level of taxation also approximates zero. Indeed, as long as $\pi_{i}<1 / 2$ the preferred level of taxation is lower than under universalism (when $\pi_{i}=1 / 2$ it is equivalent to universalism since people find themselves in both states with equal probability). This condition is satisfied in all but the most extreme of circumstances. The poor, on the other

10. The balanced budget constraint is satisfied if we assume that the poor have no income since then total per capita revenues are $(1-\pi) \cdot t$. $\sum y_{i} / N=t \cdot \sum y_{i} / N=t \cdot \bar{y}$, and total per capita outlays are $t \cdot \sum\left(y_{i} / n\right)$. $n=t \cdot \bar{y}$. We could allow for the poor to have income by inserting the term $\pi_{i} \cdot \ln \left[(1-t) \cdot y_{i}\right]$, but it makes no difference to the substantive results.

11. The model can be amended to allow for longer time horizons and discounting of the future, but it does not affect the key conclusions for our purposes. 
hand, will demand higher spending than the nonpoor as long as the probability of escaping poverty is lower than one minus the probability of falling into poverty. ${ }^{12}$ Both the lower overall public support for social spending and the division between the haves and have-nots in a means-tested system are precisely as predicted in the existing literature, including Korpi and Palme (1998).

\section{Targeted means-tested benefits in an APA world}

While private markets have made many inroads into previously public domains of social spending, one area still almost entirely nonmarket based is insurance against poverty. Whereas insurance or financial companies are happy to offer annuity plans that "insure" against outliving one's income, and while life and health insurance are increasingly offered in the market based on the credible sharing of health information, the possibility of insuring against poverty is virtually nonexistent. Both moral hazard (not doing enough to stay out of poverty) and adverse selection (people who are lazy or know they are at high risk taking out insurance) militate against market provision. Unlike medical testing, there are no certified tests of bad intentions or bad luck. In addition, some risks are effectively uninsurable because of costs. Private pension and health plans typically do not cover the risk of long-term care, for example, which quickly drains private savings and pension funds of ordinary people. Longterm care plans do exist, but they are expensive and always come with time or benefit limits. The same logic applies to long-term unemployment benefits, as well as public assistance programs that replace unemployment benefits when they run out. For these reasons unemployment insurance and means-tested benefits, which serve as insurance against poverty, have always been more or less entirely in the public domain.

With this in mind what is the structure of preferences in an APA world when public benefits are means tested? With no private insurance against poverty, all people who buy private plans are nonpoor and they can only benefit from those plans if they remain nonpoor. The nonpoor utility function with private alternatives and means-tested benefits is therefore: ${ }^{13}$

$$
\begin{aligned}
W_{i}= & \left(1-\pi_{i}\right) \cdot \ln \left[\left(1-t-p_{i}\right) \cdot y_{i}\right] \\
& +\left(1-\pi_{i}\right) \cdot \alpha \cdot \ln \left(p_{i} \cdot y_{i}\right)+\pi_{i} \cdot \alpha \cdot \ln \left(\frac{t \cdot \bar{y}}{n}\right)
\end{aligned}
$$

12. To see this substitute the probability of moving out of poverty in the next period for $1-\pi_{i}$ in eq. (7). It is easy to see that if that probability is lower than $1-\pi_{i}$ the preferred $t$ will be higher.

13. For the balanced budget constraint being satisfied, see n. 10 .
The nonpoor can allocate resources to private plans, while taxes will go to paying for benefits that only the poor (or those below a set income threshold) qualify for. The optimal tax rate for the nonpoor is now:

$$
t_{i}^{*}=\frac{\alpha \cdot \pi_{i}}{1-2 \alpha} \cdot\left(1-p_{i}\right) .
$$

Compared to the BPA world, the preferred tax level of any individual is further reduced by the share they spend on private plans, but there is always demand for public spending on a safety net as long as the probability of poverty is nonzero. Furthermore, since all nonpoor in a means-tested system cannot satisfy their demand for social insurance through the public system, they have to spend privately. In appendix A(ii) we show that in this case the demand for taxation only depends on the risk of poverty, not on income. In a probabilistic formulation similar to the previous section, support for cutting taxes is given by:

$$
\begin{aligned}
\operatorname{Pr}(\text { support for cuts }) & =\operatorname{Pr}\left[\frac{\pi_{i}}{2-\pi_{i}}+v_{i}<t\right] \\
& =\operatorname{Pr}\left[\frac{\pi_{i}}{2-\pi_{i}}-t<v_{i}\right],
\end{aligned}
$$

where $t$ is the current tax rate and $v_{i} \sim N\left(0, \sigma \prime_{i}^{2}\right)$ is a normally distributed error term.

We established above (eq. [6]) that support for universal benefits in the APA world is negatively related to income, while support for targeted spending is not-the opposite of the BPA result (and the Korpi-Palme conjecture). Yet, the APA analysis of universalistic benefits (see the section "Universalism in an APA world") made the implicit assumption that public and private alternatives are perfect substitutes, and we know that cannot be true when the private market does not insure against poverty. In this situation universal benefits will also serve insurance purposes. In appendix B we show that this does not alter our conclusion. Those who are above the threshold for opting into the market will continue to support some public spending for safety-net reasons, but when benefits are universal the demand for public insurance will decline in income because upper-end income groups oppose public spending that competes with private alternatives. The more spending is concentrated on the nonpoor, the greater this opposition. ${ }^{14}$ So in the APA world, as we go from a meanstested to a universalistic (or "encompassing") system the negative relationship between income and support for public spending becomes steeper - the opposite pattern of the BPA world.

14. Only up to a point because if the public system mimics the private, without redistribution, it again becomes attractive to higher income groups. 
Table 1. Empirical Implications of the Model

Availability of Private Alternatives

Degree of Targeting of Benefits to LowIncome Recipients

BPA

APA

Low (universalistic benefit structure, possibly with an income-dependent component)

High (progressive benefit structure with means testing)
No or small income differences in preferences. Cross-class support.

Division between poor and nonpoor: rich (poor) more likely to oppose (support)

public spending.

Note. $\mathrm{BPA}=$ before private alternatives; $\mathrm{APA}=$ after private alternatives.

(App. B provides a formal and graphical representation of this logic.)

\section{Summary}

This completes our four-way comparison of social spending preferences, which is summarized in table 1. In the BPA world, universalism (and encompassing benefits) implies broad cross-class support for the social spending, whereas means testing will divide the poor from the nonpoor-as argued in the existing literature. But in the APA world, when viable private alternatives to public provision are available, contrary to what is implied by the canonical Korpi-Palme theory, our model predicts that high-income citizens will be more opposed to additional public spending on social policies when benefits are universal (or encompassing) than when they are targeted. As table 1 highlights, taking private alternatives into account essentially turns the Korpi and Palme thesis on its head.

\section{EMPIRICAL ESTIMATION The statistical model}

In an ideal setting, we would test the empirical implications of the formal model by tracing the development of public support for the welfare state as it changes over time from a world "before" to a world "after" private alternatives have become available. Such a research design is feasible - at bestonly for individual countries where panel and time series data on public attitudes and preferences are available (see e.g., the study by Bendz [2015] on the case of Sweden). Our study, in contrast, is focused on the cross-national comparison of OECD countries, although it can (and should) be complemented with individual country studies of panel data at a later stage whenever feasible. Given the limitations of the data at hand (which we discuss in detail below), we are forced to derive indirect inferences about the difference between an
APA and a BPA world from a cross-sectional comparison of OECD countries.

Our empirical strategy to tease out differences in the dynamics of public opinion between an APA and a BPA world is twofold: First, we compare the two policy fields of unemployment and pension policy. In the former case, private alternatives to public insurance are not (yet) available, whereas private alternatives to public schemes have become more feasible in many countries in the case of pensions. Second, we make use of the cross-national variation in the extent to which private alternatives have expanded across the countries of the OECD world within the policy field of pensions. The comparison of unemployment and pension policies has certain disadvantages as the underlying risk structures (labor-market-related risks vs. life-course-related risks) are somewhat different, but faced with the challenge of finding both suitable survey data as well as detailed data on the institutional design of benefit schemes, we believe it is the best feasible comparison of an APA with a BPA scenario.

The empirical implications of our theoretical model point to the existence of a number of cross-level interactions between income and the institutional context. First, we expect a cross-level interaction between individual income on the microlevel and the degree of benefit targeting to low-income citizens (i.e., the progressivity of transfer and social insurance schemes) on the macrolevel. Second, we furthermore expect differences in the direction of the cross-level interaction between income and targeting when we compare a BPA with an APA world. To test this claim, we can either compare different policy fields or subsamples or compute a triple interaction between income, targeting, and the availability of private alternatives. We do both in the following analysis.

Our research design has limitations related to the crosssectional nature of the data. We cannot entirely rule out 
selection effects, reverse causality, or spurious correlations. For example, lower public support for the welfare state in some countries may be due to cultural, historical, or other idiosyncratic reasons that may also make it more likely that private alternatives are accepted and promoted. Also, public attitudes and preferences could affect policy output (Rehm 2011) rather than the other way around (reverse causality), and those who select into high-paying occupations could harbor more individualistic or market-oriented attitudes (see Kitschelt and Rehm 2014).

We share these concerns but emphasize several considerations in response: First, by employing two distinct comparative studies as well as by performing a number of robustness checks, we are confident that our results reveal significant and robust associations between the institutional structure of benefit schemes and patterns of public attitudes. Also, by employing country fixed effects, we can mitigate concerns that these associations are driven by country-specific idiosyncrasies. Second, our model implies heterogeneous interaction effects across policy areas and countries that are not easily accounted for by selection effects or common causes. Third, our argument is quite open to the possibility that the causal arrow between institutions and attitudes runs in both directions as policy makers respond to public demands at the same time as their policy decisions influence future expectations and preferences of citizens. Such reinforcing dynamics suggest equilibrium relationships that are not easily decomposed into discrete causal effects. Thus, in spite of the limitations of the data, we maintain that it is both sensible and meaningful to focus on the correlational implications of institutional design for patterns of public support.

\section{Data and measurement}

For our empirical analysis, we rely on data from the International Social Survey Programme (ISSP) Role of Government (RoG) IV module. Fieldwork for this survey was conducted in 2006. Our theoretical argument applies to advanced postindustrial democracies in the Western world with mature welfare states and viable private alternatives, so we cannot make use of available ISSP data for countries that fall outside the scope of our model (e.g., Uruguay, Israel, or Venezuela). The final sample consists of 20 countries, for which we have sufficient data both on the micro- and the macrolevel: Australia, Canada, the Czech Republic, Switzerland, Germany, Denmark, Spain, Finland, France, Great Britain, Hungary, Ireland, Japan, the Netherlands, Norway, New Zealand, Poland, Portugal, Sweden, and the United States. Unfortunately, there is no data for private pension spending for New Zealand, Hungary, and Poland; therefore, the number of countries drops to 17 in some regressions. The low number of macro- level units is a perennial problem in multilevel analyses (cf. Stegmueller 2011) as well as in comparative political science more generally. Nevertheless, an $n$ of 20 is sufficient to yield significant results that we believe are generalizable to our universe of cases.

The RoG module contains a battery of questions about individual preferences for public spending. The exact wording of the root question is: "Listed below are various areas of government spending. Please show whether you would like to see more or less government spending in each area."

Respondents could reply on a 5-point Likert scale ("spend much more," "spend more," "spend the same as now," "spend less," "spend much less"). For the purpose of this paper, we concentrate on spending on "unemployment benefits" and "old age pensions," since these areas of government activity are particularly suitable for testing our model (see Busemeyer and Iversen [2014] for a study of public support for education spending). We transform the 5-point variable given in the original data into a binary variable, which takes the value of 1 when individuals profess a preference for "more" or "much more" spending and 0 when they respond with "the same" or "(much) less" spending. This is consistent with the probabilistic interpretation of our model and mirrors the practices of other researchers working with the ISSP data set. It also helps to simplify the analysis, making the coefficient estimates easier to interpret.

Relative individual income is measured as income (in deciles) in the country-specific distribution of incomes divided by the country-specific mean. In addition, we control for education (in years), age, and gender. Women and older people tend to be more supportive of social spending while the opposite is true of those with high education. We also include various indicators of the individual's employment status as controls: full-time employed (the reference category); part-time employed; less than part-time employed/ staying at home/helping family member or a disabled person/out of labor force; unemployed; in education; and being retired.

At the macrolevel, we first employ an aggregate measure of the public spending share, which is defined as the share of public pension spending out of all total spending for pensions as defined in the OECD's Social Expenditure (SOCX) Database. This database distinguishes between voluntary private spending (e.g., individual retirement savings) and mandatory private spending. The latter may result from, for example, the state requiring citizens to pay into private pension schemes. We count mandatory private spending as private spending rather than public spending since the key for the model is whether people spend on a private income-related plan. In the regressions with preferences for unemployment as 
the dependent variable, we include the general level of social spending as macrolevel control (also from the SOCX database) to take into account potential feedback effects from existing policies on support for further spending increases (Wlezien 1995). ${ }^{15}$

Second, we use several measures of the degree of progressivity/low-income targeting for pension and unemployment schemes. The OECD "Benefits and Wages" database provides a wealth of data on replacement rates of social transfer schemes, depending on household composition and wage levels. ${ }^{16}$ To a certain extent, picking one particular configuration over another always entails an element of arbitrariness. We try to minimize the potential for bias by choosing a plausibly typical configuration of household characteristics. In the case of unemployment, our measure of low-income targeting is the difference in the net replacement rate in a phase of initial (not long-term) unemployment between a one-earner married couple with two children at $150 \%$ of the average wage and the same kind of couple at $67 \%$ of the average wage. Higher values on this indicator indicate stronger targeting in favor of the poor. In the case of pensions, we use the "pension progressivity index" provided by the OECD "Pensions at a Glance" project (OECD 2007, 45). This index is based on a continuum, in which a value of zero indicates the existence of a "pure insurance scheme" (OECD 2007, 44) with a constant replacement rate across income levels. In contrast, a value of 100 indicates a highly progressive scheme, where benefits are increasingly targeted to those with lower incomes. Thus, similar to our indicator for targeting in the case of unemployment schemes, higher values on this measure stand for transfer schemes, which are more in favor of low-income citizens.

Unfortunately, the measures for the institutional structure of benefits schemes are only available for more recent years. Thus, even though there are data on public attitudes and preferences for the mid-1990s from the previous ISSP Role of Government survey, our analysis has to be restricted to a cross-sectional comparison of OECD countries for the year 2006 for that reason. In the future, once the next wave of the ISSP Role of Government becomes available and the

15. In further robustness checks, we also include the level of public spending on unemployment and pensions, respectively. The inclusion of these additional control variables does not change the coefficient estimates for the remaining independent variables. Hence, to keep the number of macrolevel control variables small, we refrain from using them in the main model specifications.

16. See http://www.oecd.org/els/benefits-and-wages-statistics.htm (accessed April 27, 2017). institutional measures have been updated, it should be possible to extend it to the more recent time period.

In terms of methods, we employ multilevel logit models with cross-level interactions, which mirror the probabilistic version of our theoretical model. In the tables below, we first show results for models including the macrolevel controls plus the interactions and then for models with just the interactions plus country dummies (fixed effects). All macrolevel variables are lagged by one year, which to some extent mitigates the potential problem of endogeneity.

\section{Results}

Study I: Pensions versus unemployment. In the first study, we look at the difference in the determinants of public support for pensions versus unemployment spending (see table 2). Since we highlight the differences between an APA and a BPA world by comparing different spending areas, we focus on the cross-level interaction between income and targeting. In models 2 and 5 of table 2, we include the macrolevel controls, whereas we employ country dummies (not shown in the table) in models 3 and 6 . The number of countries drops to 17 in models 1 and 2 because of missing data for private pension spending in three countries (see comments above).

The most important finding is that the cross-level interaction between relative income and our indicators of targeting/benefit progressivity are very different across policy areas, depending on whether private alternatives are available or not. As is well known in the literature, the association between income and support for social spending is negative for both support for more government spending on unemployment and pensions (see models 1 and 4 in table 1). However, we are primarily interested in how the institutional design of transfer schemes mediates the microlevel association between income and support for spending. Both of the institutional indicators measure the degree to which transfer schemes benefit the relatively poor, with higher values indicating a higher degree of benefit progressivity/low-income targeting.

In the case of pensions, the cross-level interaction between income and benefit progressivity is positive and significant. In the case of support for spending on unemployment benefits, the cross-level interaction between income and low-income targeting, in contrast, is negative and significant as expected (see table 1). In a BPA world (unemployment policy), richer citizens are more likely to oppose spending increases as targeting increases, since this implies a stronger degree of progressive redistribution from the rich to the poor. In an APA world (pensions), however, the rich are less opposed to additional public spending for high levels of progressivity, that is, high levels of targeting. Our formal 
Table 2. Determinants of Preferences for More Public Spending on Unemployment Benefits and Old Age Pensions.

\begin{tabular}{|c|c|c|c|c|c|c|}
\hline \multirow[b]{2}{*}{ Dependent Variable } & \multicolumn{3}{|c|}{$\begin{array}{l}\text { Support for More or Much More Public } \\
\text { Spending on Old Age Pensions }=1 \\
\text { Support for Same or Less }=0\end{array}$} & \multicolumn{3}{|c|}{$\begin{array}{l}\text { Support for More or Much More Public } \\
\text { Spending on Unemployment Benefits = 1; } \\
\text { Support for Same or Less }=0\end{array}$} \\
\hline & $(1)$ & $(2)$ & (3) & $(4)$ & $(5)$ & (6) \\
\hline Relative income & $\begin{array}{c}-.427^{* * *} \\
(.0354)\end{array}$ & $\begin{array}{c}-.652^{* * *} \\
(.0632)\end{array}$ & $\begin{array}{c}-.401^{\star * *} \\
(.0479)\end{array}$ & $\begin{array}{c}-.501^{\star * *} \\
(.0390)\end{array}$ & $\begin{array}{c}-.282^{\star * *} \\
(.0835)\end{array}$ & $\begin{array}{c}-.284^{\star * *} \\
(.0835)\end{array}$ \\
\hline Gender (female) & $\begin{array}{l}.0848^{* *} \\
(.0364)\end{array}$ & $\begin{array}{l}.0826^{\star *} \\
(.0364)\end{array}$ & $\begin{array}{l}.131^{\star * *} \\
(.0341)\end{array}$ & $\begin{array}{c}-.0342 \\
(.0376)\end{array}$ & $\begin{array}{c}-.0358 \\
(.0376)\end{array}$ & $\begin{array}{c}-.0363 \\
(.0376)\end{array}$ \\
\hline Educational background & $\begin{array}{c}-.0769^{* * *} \\
(.00507)\end{array}$ & $\begin{array}{c}-.0758^{* * *} \\
(.00507)\end{array}$ & $\begin{array}{c}-.0799^{* * *} \\
(.00484)\end{array}$ & $\begin{array}{c}-.0411^{* * *} \\
(.00527)\end{array}$ & $\begin{array}{c}-.0418^{* * *} \\
(.00528)\end{array}$ & $\begin{array}{c}-.0413^{* * *} \\
(.00528)\end{array}$ \\
\hline Age & $\begin{array}{l}.0154^{* * *} \\
(.00152)\end{array}$ & $\begin{array}{l}.0156^{* * *} \\
(.00152)\end{array}$ & $\begin{array}{l}.0152^{* * *} \\
(.00141)\end{array}$ & $\begin{array}{l}.00568^{* * *} \\
(.00155)\end{array}$ & $\begin{array}{l}.00566^{* * *} \\
(.00155)\end{array}$ & $\begin{array}{l}.00573^{* * *} \\
(.00155)\end{array}$ \\
\hline Part-time worker & $\begin{array}{c}-.128^{* *} \\
(.0603)\end{array}$ & $\begin{array}{c}-.121^{\star *} \\
(.0603)\end{array}$ & $\begin{array}{c}-.101^{*} \\
(.0568)\end{array}$ & $\begin{array}{c}.0638 \\
(.0652)\end{array}$ & $\begin{array}{l}.0587 \\
(.0652)\end{array}$ & $\begin{array}{c}.0611 \\
(.0653)\end{array}$ \\
\hline Marginal employment or out of labor force & $\begin{array}{c}.00533 \\
(.0634)\end{array}$ & $\begin{array}{c}.0178 \\
(.0635)\end{array}$ & $\begin{array}{c}.0186 \\
(.0595)\end{array}$ & $\begin{array}{l}.266^{* * *} \\
(.0643)\end{array}$ & $\begin{array}{l}.256^{* * *} \\
(.0644)\end{array}$ & $\begin{array}{l}.257^{* * *} \\
(.0644)\end{array}$ \\
\hline Unemployed & $\begin{array}{l}.167 \\
(.103)\end{array}$ & $\begin{array}{l}.151 \\
(.104)\end{array}$ & $\begin{array}{l}.171^{\star} \\
(.0957)\end{array}$ & $\begin{array}{l}1.187^{* * *} \\
(.0938)\end{array}$ & $\begin{array}{l}1.185^{* * *} \\
(.0939)\end{array}$ & $\begin{array}{l}1.186^{* * *} \\
(.0940)\end{array}$ \\
\hline In education & $\begin{array}{c}-.526^{* * *} \\
(.122)\end{array}$ & $\begin{array}{c}-.517^{\star * *} \\
(.122)\end{array}$ & $\begin{array}{c}-.477^{\star * *} \\
(.115)\end{array}$ & $\begin{array}{c}-.0791 \\
(.141)\end{array}$ & $\begin{array}{c}-.102 \\
(.141)\end{array}$ & $\begin{array}{r}-.0987 \\
(.141)\end{array}$ \\
\hline Retired & $\begin{array}{r}-.131^{\star *} \\
(.0639)\end{array}$ & $\begin{array}{c}-.125^{\star} \\
(.0640)\end{array}$ & $\begin{array}{r}-.0833 \\
(.0603)\end{array}$ & $\begin{array}{r}-.142^{\star *} \\
(.0658)\end{array}$ & $\begin{array}{r}-.146^{\star *} \\
(.0658)\end{array}$ & $\begin{array}{r}-.146^{\star *} \\
(.0658)\end{array}$ \\
\hline Public share in spending on pensions & $\begin{array}{c}2.082^{\star} \\
(1.084)\end{array}$ & $\begin{array}{c}2.100^{*} \\
(1.092)\end{array}$ & & & & \\
\hline Pension progressivity index & $\begin{array}{c}.00942 \\
(.00662)\end{array}$ & $\begin{array}{c}.00417 \\
(.00678)\end{array}$ & & & & \\
\hline Public social spending, percentage of GDP & & & & $\begin{array}{c}-.00920 \\
(.0502)\end{array}$ & $\begin{array}{c}-.00898 \\
(.0502)\end{array}$ & \\
\hline Low-income targeting of unemployment scheme & & & & $\begin{array}{c}-.0141 \\
(.0201)\end{array}$ & $\begin{array}{r}-.00457 \\
(.0203)\end{array}$ & \\
\hline Income $\times$ pension progressivity & & $\begin{array}{l}.00483^{* * *} \\
(.00112)\end{array}$ & $\begin{array}{c}.00156^{*} \\
(.000859)\end{array}$ & & & \\
\hline Income $\times$ targeting of unemployment benefits & & & & & $\begin{array}{c}-.0100^{\star * *} \\
(.00344)\end{array}$ & $\begin{array}{c}-.0100^{* * *} \\
(.00344)\end{array}$ \\
\hline Constant & $\begin{array}{l}-.743 \\
(1.041)\end{array}$ & $\begin{array}{l}-.539 \\
(1.050)\end{array}$ & $\begin{array}{l}.710^{\star * *} \\
(.113)\end{array}$ & $\begin{array}{c}.162 \\
(1.333)\end{array}$ & $\begin{array}{l}-.0392 \\
(1.334)\end{array}$ & $\begin{array}{c}-1.341^{* * *} \\
(.131)\end{array}$ \\
\hline Country dummies & No & No & Yes & No & No & Yes \\
\hline Observations & 17,285 & 17,285 & 19,673 & 19,475 & 19,475 & 19,475 \\
\hline No. of countries & 17 & 17 & 20 & 20 & 20 & 20 \\
\hline
\end{tabular}

Note. Standard errors in parentheses.

${ }^{*} p<.1$.

${ }^{* *} p<.05$.

${ }^{* * *} p<.01$.

model explains this finding by pointing out that in this scenario, the rich are more likely to demand a progressive, flat-rate system of benefit provision as an instrument of basic social insurance against poverty, while resorting to private alternatives for the income-related components for the bulk of their pensions.
The association between targeting and support for unemployment spending is very robust, independent of whether we use country dummies (model 6) or individual macrolevel variables (model 5). The effect sizes and levels of statistical significance are somewhat reduced when using country dummies instead of individual macrolevel variables in the case of 


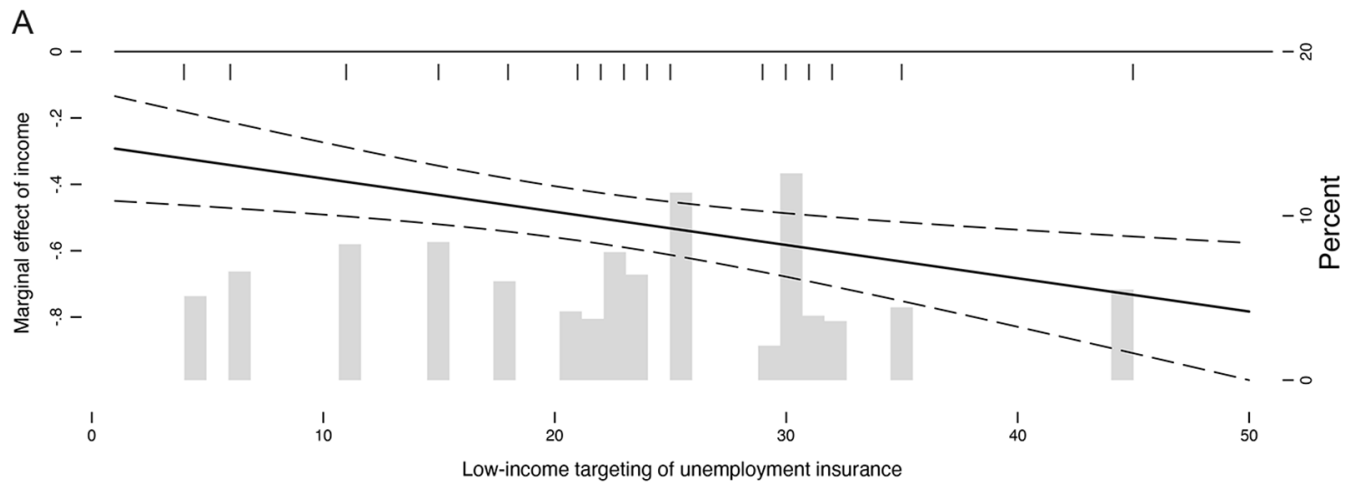

B
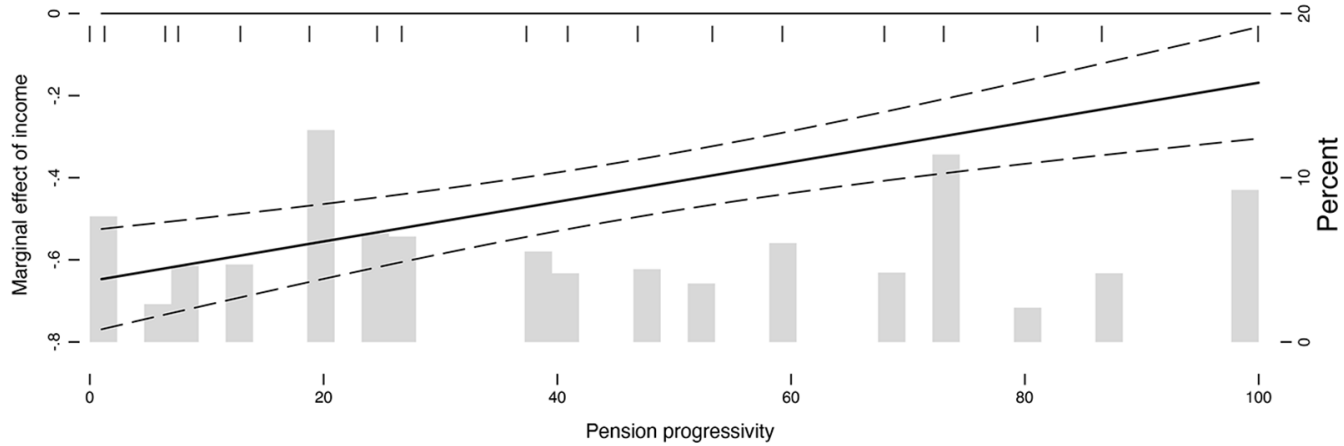

Figure 1. Cross-level interactions between income and low-income targeting of unemployment $(A)$ and pension $(B)$ schemes

support for pension spending (model 3 vs. model 2$).{ }^{17}$ Figure 1 is a graphical depiction of the cross-level interactions. The top half displays the negative interaction for the case of unemployment, while the lower half shows the positive one for pensions.

The figures clearly show that the marginal effect of income on support for unemployment benefits is negative and significant already for very low levels of the institutional indicator of low-income targeting (real-world cases would be France and Portugal): the marginal effect of income roughly doubles in size from -0.3 to more than -0.6 for countries with a high degree of low-income targeting of benefits (Norway is the country with the highest value in the sample). In the latter case, the rich are much more opposed to spending increases than in the former case, which corresponds to the standard Korpi and Palme argument. In a setting where transfer schemes primarily benefit low-income citizens, the rich are for obvious reasons opposed to higher levels of government spending on these policies.

For public pensions in the APA world the size of the negative marginal effect of income on support for additional

17. This is not due to the reduced number of cases in model 2 (related to missing data on private pension spending for Hungary, New Zealand, and Poland as explained above). Running the specification of model 2 without these three countries does not change the coefficient estimates (results available upon request). public spending is strongest for low levels of progressivity (e.g., in the Netherlands and Hungary). It increases from about -0.6 to -0.2 in countries with a high degree of pension progressivity (e.g., Ireland and New Zealand), barely remaining statistically significant in the latter cases. Again, the mediating effect of institutional contexts does not completely cancel out the negative association between income and spending support - which is also true in the theoretical model (see app. B)but it is a strong indicator that institutions matter. In the case of pensions, the rich are more likely to oppose additional public spending on pensions when the scheme is less redistributive. This is a finding that runs counter to the standard Korpi and Palme argument because it could have been expected that the rich are more in favor of a higher degree of income dependency in benefits - similar to what we observed for the case of unemployment benefits.

We explain this counterintuitive finding by pointing to the existence of private alternatives in the case of pensions, which are lacking in the case of unemployment insurance. When private alternatives are available, support among the upper and middle classes for additional spending on public schemes deteriorates as they can resort to more attractive alternatives in the private sector. But they still demand public insurance against risks that are not fully covered in the market such as poverty, that is, in this case the risk of not having enough private pensions to provide income for a very long 
postretirement life. Correspondingly, we find that in countries with more progressive pension schemes, the opposition against public spending among those with higher incomes is significantly reduced. Taken together, this could indicate strong support for a mixed public-private model of provision: there is more support (or at least less opposition) among those with higher incomes for additional public spending in pension systems with a high degree of progressivity (targeting to the poor). Vice versa, there is significantly more opposition against further public spending in countries with incomedependent benefits, indicating that in these cases, citizens with higher incomes prefer private alternatives.

Table 3 provides estimates of predicted probabilities for popular support for additional spending on unemployment and pensions policies, depending on the level of progressivity of benefit schemes. The table presents a different perspective of the findings displayed in figure 1 and table 2, providing additional support for our argument. First of all, and most importantly, the table shows that the effects are mostly attributable to changing support levels among the rich rather than among the poor: support for additional spending on unemployment benefits among the poor is essentially independent of the degree of targeting of benefits, and it only increases slightly (as would be expected) in the case of pensions. In contrast, support among the rich for additional spending on unemployment - which is at a much lower level even for low levels of targeting-drops even further for high levels of targeting (as a reminder, model 2 in table 2 has confirmed that this interaction is statistically significant). In the case of pensions, changes in support for additional spending among the rich are even more pronounced, increasing from about $45 \%$ to $62 \%$, almost negating the otherwise negative association between income and spending support (see panel $B$ in fig. 1).

Second, the latter finding also provides some support for the empirical implication of our model that income-related conflicts are more muted in a system with private alternatives and strong targeting compared to a scenario with private alternatives and universalist provision. The difference in support for additional public spending on pensions between high- and low-income citizens is about 6 percentage points in the latter case, but about 20 percentage points in the former. We see the reverse effect in the case of unemployment, where income-related conflict is more pronounced in a scenario with high targeting compared to low targeting (20 vs. 12 percentage points).

Finally, we should note that the control variables perform as expected. Similar to income, higher levels of education are associated with less support for additional public spending on either unemployment benefits or old age pensions. Women are more likely to support additional spending on pensions but not on unemployment benefits. Again as expected, age is positively associated with support for additional spending on unemployment and pensions. Controlling for age, the retired are slightly less in favor of additional public spending, most probably indicating the highest degree of support in the age cohort shortly before retirement. The unemployed and those in marginal employment or out of the labor force are more likely to support additional spending on unemployment benefits, which is clearly related to self-interest (and implied by the model). Similarly, those still in education are less likely to support additional spending on pensions, potentially hinting at a generational cleavage in attitudes (Busemeyer, Goerres, and Weschle 2009). We also find indications of a more general feedback effect, with citizens living in countries with a high public share in pension spending also being more supportive of additional spending on pensions.

Study II: Public versus private pension schemes. In the preceding section we demonstrated how the microlevel association between income and support for additional public spending varied across the two policy fields of unemployment

Table 3. Predicted Probabilities for Popular Support for Additional Spending on Unemployment and Pensions Policies, by Level of Targeting

\begin{tabular}{|c|c|c|c|c|}
\hline & \multicolumn{2}{|c|}{ Unemployment (BPA World) } & \multicolumn{2}{|c|}{ Pensions (APA World) } \\
\hline & Low Targeting & High Targeting & Low Targeting & High Targeting \\
\hline Low income & $.34173(.0500)$ & $.34652(.0458)$ & $.65639(.0459)$ & $.68622(.0523)$ \\
\hline High income & $.22143(.0404)$ & $.14809(.0285)$ & $.45432(.0497)$ & $.62445(.0569)$ \\
\hline
\end{tabular}

Note. Estimates were obtained via the margins command in Stata. Figures in parentheses indicate standard errors. Individuals with "low incomes" are defined as being in the lowest two deciles of the income distribution ( $47.2 \%$ of individuals across the whole sample), individuals with "high incomes" as those in the upper half of the income distribution ( $21.1 \%$ of individuals across the whole sample). For the targeting measures, the continuous measures used in table 1 were dichotomized into two equally sized categories (high and low). 
and pension policies. We compared these two policies as examples of a state of the world with and without private alternatives. Yet, we cannot be sure that the differences we identified are not related to other differences between the two policy areas. To address this concern, we consider variation within the policy area of pensions. Pension systems in the OECD countries differ not only with regard to the degree to which benefits are means tested (our core macrolevel explanatory variable) but also with regard to the share of spending that stems from private rather than public sources. We take the latter as a measure of the availability of private alternatives and then ask how benefit structure affects preferences for public spending.

Table A1 (available online) presents findings of regressions of individual-level support for additional public spending on old age pensions. Model 1 includes several terms to model a triple interaction between pension progressivity, the public spending share, and income on the microlevel. Figure 2 is a graphical presentation of this triple interaction. For models 2 and 3, we instead split the sample roughly in half based on the level of public spending on pensions; the cut-off point is a share of about $80 \%$. The number of country cases is reduced to nine and eight, respectively, in the subsamples, which is below the number commonly recommend for multilevel cross-country regressions. Therefore, the results from models 2 and 3 should be treated with due caution and mainly serve as a robustness check for model 1 .

Our main findings can be summarized as follows: both the public spending share and pension progressivity mediate the negative effect of income, confirming the findings across policy areas. A graphical presentation is helpful to understand these complex associations (see fig. 2). The figure shows

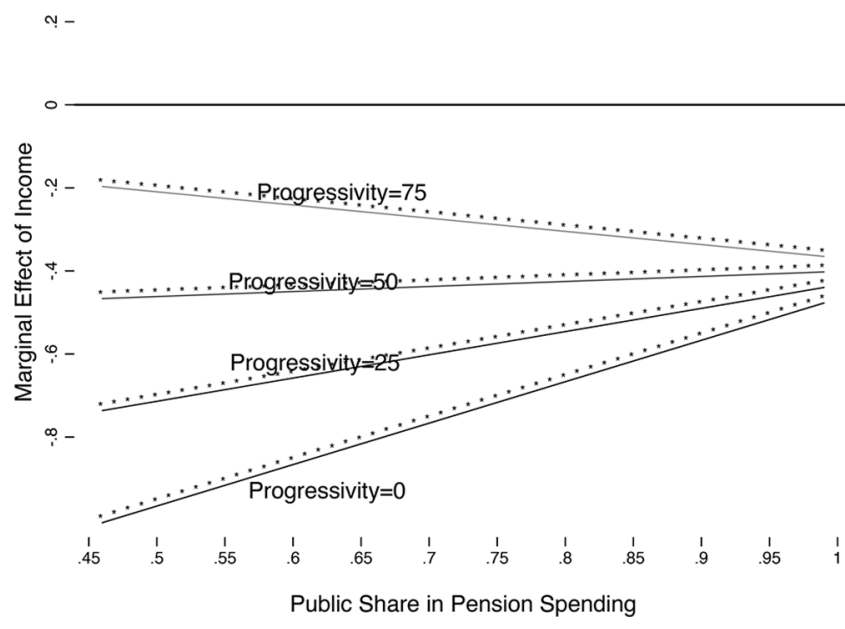

Figure 2. Triple interaction between relative income, pension progressivity, and public spending share on pensions. that income-related conflict about additional public spending on pensions decreases as the public spending share increases. This can be seen by the converging of the regression lines toward the right side of the graph. In systems with a strong private component, income-based conflict is strong in nonprogressive systems, while it is muted in means-tested systemscontrary to the standard Korpi-Palme conjecture but consistent with the APA scenario in our model. In public systems there are no significant differences in preferences across incomes, which is in line with the standard Korpi-Palme argument and the BPA scenario in our model.

Taken as a whole, the evidence suggests that even though we focus on variation within the policy field of pensions rather than comparing unemployment with pensions as above, we find a similar dynamic at work: in those cases where private alternatives are more viable and available, increasing the progressivity of benefit schemes decreases the opposition of highincome citizens against additional public spending on pensions. In figure 2 , this would be equivalent to moving from the lower corner on the left straight up to the zero line. Put differently, income-related conflict about additional public spending on pensions is strongest in systems with a strong private component, and high-income citizens are the most opposed to increasing public spending when benefit schemes are the least progressive. Our interpretation is that means-tested schemes offer a last-resort insurance against poverty that is not available in the market, whereas income-dependent, yet still somewhat redistributive, public schemes crowd out the existing private, and entirely nonredistributive, income-dependent schemes.

Our core finding is confirmed in the analyses of subsamples (models 2 and 3 in table A1). When only looking at countries with a below-average share in public spending on pensions (model 2), we find a positive cross-level interaction between income and pension progressivity, similar to what we found for the sample as a whole. In countries with a high public share in spending (model 3), there is no such association, keeping in mind that the statistical significance of interactions is likely to be affected by the small number of higher-level units (countries) in this case. This confirms that the progressivity of pension benefit schemes matters mostly in countries with a low public share as income-related conflict about additional public spending is muted in countries with a high public share.

Another perspective on our findings is presented in table 4, where we display predicted probabilities depending on degree of targeting of benefits and the public share of pension spending. Similar to table 3, we find that the magnitude of income-related conflict in the APA world decreases when moving from a low to a high degree of targeting as rich 
Table 4. Predicted Probabilities for Popular Support for Additional Public Spending on Pensions, by Level of Targeting and Public Share in Financing

\begin{tabular}{|c|c|c|c|c|}
\hline & \multicolumn{2}{|c|}{$\begin{array}{l}\text { High Public Share of Pension } \\
\text { Spending (BPA World) }\end{array}$} & \multicolumn{2}{|c|}{$\begin{array}{c}\text { Low Public Share of Pension } \\
\text { Spending (APA World) }\end{array}$} \\
\hline & Low Targeting & High Targeting & Low Targeting & High Targeting \\
\hline Low income & $.71309(.0501)$ & $.63584(.1468)$ & $.58545(.0889)$ & $.65578(.0593)$ \\
\hline High income & $.51638(.0615)$ & $.43214(.1720)$ & $.38327(.0884)$ & $.59975(.0624)$ \\
\hline
\end{tabular}

Note. Estimates were obtained via the margins command in Stata. Figures in parentheses indicate standard errors. Individuals with "low incomes" are defined as being in the lowest two deciles of the income distribution ( $47.2 \%$ of individuals across the whole sample), individuals with "high incomes" as those in the upper half of the income distribution ( $21.1 \%$ of individuals across the whole sample). For the institutional measures, the continuous measures used in table 1 were dichotomized into two equally sized categories (high and low).

individuals become more supportive of targeted benefit provision (at the same time as low-income individuals also become more supportive of further public spending in this scenario). Still, the gap in support decreases from about 20 percentage points in the low targeting scenario to a bit more than 5 percentage points in the high targeting scenario. Conversely, support among the rich for additional public spending decreases in the BPA world when moving from low to high targeting. What is somewhat against our expectations is the fact that in this case, support among the lowincome respondents also decreases, whereas we would have expected it to remain constant (as in table 3) or even increase. The decrease is commensurate with the decrease in support among the rich; therefore there is no significant change in the extent of income-related conflict in the BPA world. This represents an interesting puzzle for all existing models, but our main contribution is to show the effects of introducing private alternatives, which are all consistent with our expectations.

Our results invite speculation about the politics of benefit targeting. In a system with good private alternatives and a large portion of the middle classes opting into these alternatives we may expect a majority to favor a public system that is entirely focused on serving a safety net function. Although we have not explicitly modeled the politics of institutional design, the conjecture receives some support in the data (see fig. A3 in the online app. C). In our sample, the bivariate correlation between public share and progressivity is -0.54 . While there are exceptions (notably the Netherlands and the Czech Republic), countries with a lower share of public spending tend to exhibit a more progressive pension scheme. Put differently, the public pillar in pension systems of liberal welfare state regimes such as Ireland, the United Kingdom, Canada, or Australia provides a strongly progressive basic insurance to be topped up with privateincome-dependent benefits. In contrast, pension systems in countries like Germany, Finland, Portugal, France, and Spain provide income-dependent benefits via the public pillar(s). This implies that support from the middle- and upper-income classes for public instead of private provision could be conditional on the existence of a benefit structure that provides concrete benefits for those in the upper half of the income distribution. Statistically, the correlation between the two macrolevel indicators is somewhat problematic as it depresses the individual explanatory power of each of these variables. However, as the significant scattering of country cases in figure A2 shows, they still represent two distinctly different institutional dimensions of pension systems.

\section{CONCLUSIONS AND DISCUSSION}

Our paper began with the observation that private social spending is rising across the OECD world, while public social spending remains stagnant. Our core research question was to analyze whether the rise of private alternatives in many fields of welfare state activity have undermined the supporting coalitions for sustaining a public, universalist welfare state model. In a seminal contribution, Korpi and Palme (1998) highlighted the potential trade-offs between universalist policies and public support (see also Brady and Bostic 2015): in order to maintain the support of the wealthy middleand upper-income classes for public provision and financing of the welfare state, benefit schemes should be designed in a way as to provide concrete benefits for those in the upper half of the income distribution, that is, benefits should be income dependent.

Our paper provides an important extension of this argument by showing how the existence of private alternatives changes the dynamics of public support in key ways. We find 
that the Korpi-Palme thesis holds in a world without (or before) private alternatives to public provision. Once private alternatives are viable and well established, however, highincome citizens become opposed to expanding public spending on benefits schemes when these are universal or even income dependent. Instead, they seem to prefer a public basic insurance scheme, even if this scheme provides relatively more benefits to low-income citizens. This implies that the availability of private alternatives undermines support for a comprehensive welfare state among the affluent, while shoring up support for a residual welfare state.

From the perspective of Korpi and Palme (1998), this is a counterintuitive finding, but it has important implications for the future viability of the public welfare state. In fact, our analysis can be interpreted as an indication of strong feedback effects. In a world without or with weakly developed private alternatives, income-related conflicts about public involvement are muted, documenting a strong consensus on the need for public provision. But once private alternatives are introduced, support for continued public provision is undermined by the fact that high-income citizens opt out of public schemes and in turn become more supportive of a selective rather than a universalist model of the welfare state. The public pillar is supposed to provide basic insurance to low-income citizens, but private alternatives are increasingly preferred to public schemes for the bulk of social insurance against major life course risks such as old age. The encompassing welfare state still has strong supporters in the middle class, but they can no longer rely on allies in the upper-middle classes. Thus, the universalist model of the welfare state faces two challenges: one is the direct opting out of higher-income groups; the other is the indirect drop in support for continued public provision among the same groups. The means-tested aspects of the welfare state, on the other hand, appear to be politically secure.

\section{ACKNOWLEDGMENTS}

Previous versions of this paper were presented at the "State and Capitalism since 1800" seminar at the Center for European Studies, Harvard, and the conference "Public Opinion and Policy Feedback" at the University of Konstanz. We thank the participants of these events as well as the anonymous reviewers and the editor of this journal for helpful comments and suggestions.

\section{REFERENCES}

Andreß, Hans-Jürgen, and Thorsten Heien. 2001. "Four Worlds of Welfare State Attitudes? A Comparison of Germany, Norway, and the United States." European Sociological Review 17 (4): 337-56.
Baldwin, Peter. 1990. The Politics of Social Solidarity: Class Bases of the European Welfare State, 1875-1975. New York: Cambridge University Press.

Bendz, Anna. 2015. "Empowering the People: Public Responses to Welfare Policy Change." Social Policy and Administration 51 (1): 1-19.

Brady, David, and Amie Bostic. 2015. "Paradoxes of Social Policy: Welfare Transfers, Relative Poverty, and Redistribution Preferences.” American Sociological Review 80 (2): 268-98.

Brooks, Clem, and Jeff Manza. 2006. "Social Policy Responsiveness in Developed Democracies." American Sociological Review 71 (3): 474-94.

Brooks, Clem, and Jeff Manza. 2007. Why Welfare States Persist: The Importance of Public Opinion in Democracies. Chicago: University of Chicago Press.

Busemeyer, Marius R., Achim Goerres, and Simon Weschle. 2009. "Attitudes towards Redistributive Spending in an Era of Demographic Ageing: The Rival Pressures from Age and Income in 14 OECD Countries." Journal of European Social Policy 19 (3): 195-212.

Busemeyer, Marius R., and Torben Iversen. 2014. "The Politics of Opting Out: Explaining Educational Financing and Popular Support for Public Spending.” Socio-Economic Review 12 (2): 299-328.

Calzada, Ines, and Eloisa del Pino. 2008. "Perceived Efficacy and Citizens' Attitudes towards Welfare State Reform.” International Review of Administrative Sciences 74 (4): 555-74.

Cammett, Melani, Julia Lynch, and Gavril Bilev. 2016. "The Influence of Private Health Care Financing on Citizen Trust in Government." Perspectives on Politics 13 (4): 938-57.

Dowding, Keith, and Peter John. 2008. "The Three Exit, Three Voice and Loyalty Framework: A Test with Survey Data on Local Services." Political Studies 56:288-311.

Edlund, Jonas. 2006. "Trust in the Capability of the Welfare State and General Welfare State Support: Sweden, 1997-2002.” Acta Sociologica 49 (4): 395-417.

Esping-Andersen, Gøsta. 1990. The Three Worlds of Welfare Capitalism. Princeton, NJ: Princeton University Press.

Estévez-Abe, Margarita, Torben Iversen, and David Soskice. 2001. "Social Protection and the Formation of Skills: A Reinterpretation of the Welfare State." In Peter A. Hall and David Soskice, eds., Varieties of Capitalism. Oxford: Oxford University Press, 145-83.

Gingrich, Jane R. 2011. Making Markets in the Welfare State: The Politics of Varying Market Reforms. New York: Cambridge University Press.

Jaeger, Mads Meier. 2006. "Welfare Regimes and Attitudes towards Redistribution: The Regime Hypothesis Revisited." European Sociological Review 22 (2): 157-70.

Jaeger, Mads Meier. 2009. "United but Divided: Welfare Regimes and the Level and Variance in Public Support for Redistribution." European Sociological Review 25 (6): 723-37.

Jordan, Jason. 2013. "Policy Feedback and Support for the Welfare State." Journal of European Social Policy 23 (2): 134-48.

Kitschelt, Herbert, and Philipp Rehm. 2014. "Occupations as a Site of Political Preference Formation.” Comparative Political Studies 47 (12): 1670-706.

Klitgaard, Michael Baggesen. 2007. "Do Welfare State Regimes Determine Public Sector Reforms? Choice Reforms in American, Swedish and German Schools.” Scandinavian Political Studies 30 (4): 444-68.

Korpi, Walter, and Joakim Palme. 1998. "The Paradox of Redistribution and Strategies of Equality: Welfare State Institutions, Inequality, and Poverty in the Western Countries." American Sociological Review 63 (5): 661-87.

Kumlin, Staffan, and Isabelle Stadelmann-Steffen. 2014. "Citizens, Policy Feedback, and European Welfare States.” In Staffan Kumlin and Isabelle Stadelmann-Steffen, eds., How Welfare States Shape the Democratic Public: Policy Feedback, Participation, Voting, and Attitudes. Cheltenham: Elgar, 3-16. 
Larsen, Christian Albrekt. 2008. "The Institutional Logic of Welfare Attitudes: How Welfare Regimes Influence Public Support." Comparative Political Studies 41 (2): 145-68.

Lindh, Arvid. 2015. "Public Opinion against Markets? Attitudes towards Market Distribution of Social Services - a Comparison of 17 Countries." Social Policy and Administration 49 (7): 887-910.

Meltzer, Allan H., and Scott F. Richard. 1981. "A Rational Theory of the Size of Government.” Journal of Political Economy 89:914-17.

Moene, Karl Ove, and Michael Wallerstein. 2001. "Inequality, Social Insurance, and Redistribution.” American Political Science Review 95 (4): 859-74.

Naczyk, Marek, and Bruno Palier. 2014. "Feed the Beast: Finance Capitalism and the Spread of Pension Privatization in Europe." SSRN. https:// doi.org/10.2139/ssrn.2551521.

OECD (Organization for Economic Cooperation and Development). 2007. Pensions at a Glance: Public Policies across OECD Countries. Paris: OECD.

Pierson, Paul. 1994. Dismantling the Welfare State? Reagan, Thatcher, and the Politics of Retrenchment. Cambridge: Cambridge University Press.

Pierson, Paul. 2001. The New Politics of the Welfare State. Oxford: Oxford University Press.
Rehm, Philipp. 2011. "Social Policy by Popular Demand." World Politics 63 (2): 271-99.

Rothstein, Bo. 1998. Just Institutions Matter: The Moral and Political Logic of the Universal Welfare State. Cambridge: Cambridge University Press.

Stegmueller, Daniel. 2011. "How Many Countries for Multilevel Modeling? A Comparison of Frequentist and Bayesian Approaches." American Journal of Political Science 57 (3): 748-61.

Svallfors, Stefan. 1997. "Worlds of Welfare and Attitudes to Redistribution: A Comparison of Eight Western Nations." European Sociological Review 13 (3): 283-304.

Svallfors, Stefan. 2012. "Welfare States and Welfare Attitudes." In Stefan Svallfors, ed., Contested Welfare States: Welfare Attitudes in Europe and Beyond. Stanford, CA: Stanford University Press, 1-24.

Wlezien, Christopher. 1995. "The Public as Thermostat: Dynamics of Preferences for Spending.” American Journal of Political Science 39 (4): 981-1000.

Zhu, Ling, and Christine S. Lipsmeyer. 2015. "Policy Feedback and Economic Risk: The Influence of Privatization on Social Policy Preferences." Journal of European Public Policy 22 (10): 1489-511. 